\title{
The Association Between Smartphone Use and Breast Cancer Risk Among Taiwanese Women: A Case-Control Study
}

This article was published in the following Dove Press journal: Cancer Management and Research

\author{
Ya-Wen Shih (D) \\ Chin-Sheng Hung $\mathbb{D}^{2,3}$ \\ Cheng-Chiao Huang ${ }^{4}$ \\ Kuei-Ru Chou (iD) ${ }^{1,5-7}$ \\ Shu-Fen $\mathrm{Niu}^{8,9}$ \\ Sally Chan (1D ${ }^{10}$ \\ Hsiu-Ting Tsai $\mathbb{D}^{1,8}$ \\ 'School of Nursing, College of Nursing, \\ Taipei Medical University, Taipei, Taiwan; \\ ${ }^{2}$ Department of Surgery, School of \\ Medicine, College of Medicine, Taipei \\ Medical University, Taipei, Taiwan; \\ ${ }^{3}$ Division of General Surgery, \\ Department of Surgery, Shuang Ho \\ Hospital, Taipei Medical University, New \\ Taipei City, Taiwan; ${ }^{4}$ Division of Breast \\ Surgery, Department of Surgery, Taipei \\ Medical University Hospital, Taipei, \\ Taiwan; ${ }^{5}$ Center for Nursing and \\ Healthcare Research in Clinical Practice \\ Application, Wan Fang Hospital, Taipei \\ Medical University, Taipei, Taiwan; \\ ${ }^{6}$ Department of Nursing, Taipei Medical \\ University-Shuang Ho Hospital, New \\ Taipei City, Taiwan; ${ }^{7}$ Psychiatric Research \\ Center, Taipei Medical University \\ Hospital, Taipei, Taiwan; ${ }^{8}$ Post-Baccalaure \\ ate Program in Nursing, College of \\ Nursing, Taipei Medical University, Taipei, \\ Taiwan; ${ }^{9}$ Department of Nursing, Shin \\ Kong Wu Ho Su Memorial Hospital, \\ Taipei, Taiwan; ${ }^{10}$ UON Singapore \\ Campus, Univesrity of Newcastle, \\ Newcastle, NSW, Australia
}

Correspondence: Hsiu-Ting Tsai

Email hsiuting@tmu.edu.tw
Introduction: Breast cancer is a common malignancy worldwide. Smartphones have gradually become indispensable to our modern lives and have already changed lifestyles of human beings. To our best knowledge, no study has investigated the relationship between smartphone use and breast cancer. This case-control study purposely investigated the relationship between smartphone use and breast cancer risk.

Materials and Methods: This was a case-control study comprising 894 healthy controls and 211 patients with breast cancer. All participants were asked to respond to standard questionnaires to collect information on sleep quality, smartphone addiction, and smartphone use.

Results: Participants with smartphone addiction had a significantly higher 1.43 -fold risk of breast cancer. Individuals with the habitual behavior of smartphone use $>4.5$ minutes before bedtime had a significantly increased 5.27-fold risk of breast cancer compared to those who used a smartphone for $\leq 4.5$ minutes before bedtime. Additionally, a closer distance between the smartphone and the breasts when using the smartphone exhibited a significantly increased 1.59-fold risk. Participants who carried their smartphone near their chest or waist-abdomen area had significantly increased 5.03-fold and 4.06-fold risks of breast cancer, respectively, compared to those who carried the smartphone below the waist. Moreover, there was a synergistic effect of smartphone addiction and smartphone use of $>4.5$ minutes before bedtime which increased the breast cancer risk.

Conclusion: Excessive smartphone use significantly increased the risk of breast cancer, particularly for participants with smartphone addiction, a close distance between the breasts and smartphone, and the habit of smartphone use before bedtime.

Keywords: smartphone addiction, breast cancer, women, sleep quality

\section{Introduction}

According to the International Telecommunication Union (ITU), the number of smartphone subscriptions over the last decade increased ninefold reaching 7 billion users worldwide in 2014. ${ }^{1}$ In the past decade, smartphones have gradually become one of our indispensable accessories, with the majority of devices providing access to portable internet service, and people usually text-messaging instead of talking, and with the addition of applications (apps) for e-shopping or binge-watching TV series through the smartphone. With advances in science and technology, the functions of smartphones have greatly increased, they have already changed human lifestyles worldwide, ${ }^{1-4}$ and their impacts need to be assessed. 
Breast cancer is the most commonly diagnosed malignancy among females, with about 1.38 million women being diagnosed with breast cancer worldwide each year. ${ }^{5}$ According to the cancer registry statistics of the Health Promotion Administration (HPA) in Taiwan, the incidence of breast cancer has increased in the past 20 years, it has exceeded cervical cancer, and it has become the most common female cancer since 2003 . ${ }^{6}$

People are spending more and more time on their phones, with use having risen sharply in recent decades. ${ }^{1}$ Radiofrequency radiation emitted by smartphones is thought to be associated with greater concerns about health risks and cancer-related issues. ${ }^{7-12}$ It was found that radiofrequency radiation exposure caused mammary cell damage and reactive oxygen species (ROS) formation, ${ }^{13,14}$ which are the primary causes of DNA strand breaks that can lead to cell death. ${ }^{12,15}$ Also, it was reported that as smartphones emit light, they can suppress melatonin production, a sleep-promoting hormone. ${ }^{16}$ Numerous current evidence has demonstrated that excessive use of a smartphone (due to internet addiction) before bedtime can result in poor sleep quality. ${ }^{17,18}$ A meta-analysis study by Alimoradi et $\mathrm{al}^{19}$ indicated that internet addiction is significantly associated with sleep problems (with an overall pooled odds ratio (OR) of 2.20 and $95 \%$ confidence interval (CI) of 1.77 2.74) and sleep duration (with an overall pooled standardized mean difference (SMD) of $-0.24 \mathrm{~h}$ and $95 \% \mathrm{CI}$ of -0.38 to $-0.10 \mathrm{~h}$ ). Chronic suppression of melatonin, poor sleep quality, and delayed night sleep can lead to circadian rhythm disturbances, especially when people use the smartphone for surfing the internet before bedtime day after day, which may produce negative health outcomes. ${ }^{18}$

Moreover, academic researchers have demonstrated that smartphone use increases incidences of brain tumors, ${ }^{20-22}$ parotid cancer, ${ }^{23,24}$ acoustic neuromas, ${ }^{23,25}$ non-Hodgkin's lymphomas, ${ }^{26}$ and testicular cancer. ${ }^{27}$ We hypothesized that excessive use of smartphones can increase the risk of breast cancer by non-ionizing radiofrequency exposure or by suppressing melatonin production. ${ }^{12,15,28,29}$ However to our best knowledge, no study has investigated this relationship. The purpose of this study was to investigate the association between smartphone use and breast cancer risk.

\section{Materials and Methods Study Design and Participants}

This was a case-control study. Participants were recruited between November 2017 and April 2018 from the breast surgery outpatient department of a medical university hospital that provides professional treatment and consultation for breast disease. All participants from the hospital provided written informed consent before they were allowed to participate, and the study protocol was approved by the medical university hospital's institutional review board (N201709040). The inclusion criteria for the case group included (1) participants aged over 20 years and capable of responding to our questionnaires; (2) having a diagnosis of breast cancer with a proven pathological record of histological confirmation by the International Classification of Disease ninth revision code (ICD-9): 174.0 174.9; (3) having been diagnosed with breast cancer no more than 3 months prior to the recruitment interview and without being comorbid with other cancers; and (4) having agreed to participate in the study. The inclusion criteria for the control group included: (1) participants aged over 20 years and capable of responding to our questionnaires; (2) with no history of any cancer; and (3) agreeing to participate in the study. To increase the sample size and generalizability, we set the ratio of cases to controls as 1:4. Our controls were recruited from the outpatient department and also from an online survey on the internet. We embedded a questionnaire link to a women's association website. For our controls from the online survey, the selection criteria were the same as for participants who were from the outpatient department. All participants were asked to pay attention to the instructions of the standardized questionnaires before they began to fill them out. Sonographic, ultrasound, or mammographic results were also collected from chart-records or provided by participants themselves. Those with no abnormalities in the above screening records were assigned as potential controls.

\section{Instruments/Data Collection}

The self-constructed questionnaire collected demographic information, including age, educational level, results of breast cancer screening records, family history of breast cancer, and details of behaviors of smartphone use, such as the frequency and duration of smartphone use per day, placement of the smartphone when carrying it, use of a smartphone before sleep at night, sleep quality, and years of surfing the internet with a smartphone.

Sleep quality was assessed using the Chinese version of the Pittsburgh Sleep Quality Index (PSQI) translated by Tsai et al based on the original version. ${ }^{30,31}$ The PSQI is a self-rated measure of sleep quality, that consists of seven components, including subjective sleep quality, sleep 
latency, sleep time, sleep efficiency, sleep disturbances, hypnotic drug usage, and daytime dysfunction. Possible scores of the Chinese version of the PSQI range 0 21, with a higher score indicating a worse sleep quality. ${ }^{31}$ An overall PSQI score of $>5$ can be used to identify sleep problems. The Chinese version of the PSQI had an overall reliability coefficient of $0.82 \sim 0.83$ for all participants, which indicates a high degree of internal consistency, and a test-retest reliability coefficient of $0.85 .^{31}$

The Smartphone Addiction Inventory-Short Form (SPAI-SF) was used to evaluate smartphone addiction; ${ }^{32}$ it is a 10-item self-reporting instrument consisting of four dimensions, including compulsive behavior, functional impairment, withdrawal, and tolerance. The total SPAISF score is obtained by summing the scores of each dimension, on a 4-point Likert scale ranging from 1 (strongly disagree) to 4 (strongly agree). The SPAI-SF demonstrated good internal consistency with Cronbach's $\alpha$ of 0.84 . The area under the receiver operating characteristics (ROC) curve (AUC) was 0.709 , and a cutoff point of $24 / 25$ was best for discriminating cases of smartphone addiction from diagnostic negatives (with diagnostic accuracy of $74.6 \%$, Youden index of 0.360 , and specificity of $80.5 \%$ ). Therefore, participants with a total score of $\geq 25$ points were determined to be people with smartphone addiction. $^{32}$

\section{Sample Size Calculation and Statistical Power}

The sample size was calculated based on a previous study by Hardell et $\mathrm{al}^{22}$ assuming $95 \%$ confidence intervals (CIs) and $p=0.05$, and adjusting for other confounders. Our sample size had at least $90 \%$ power to detect a 1.7 -fold increased risk in the susceptibility to breast cancer and smartphone addiction.

\section{Statistical Analysis}

Distributions of participant characteristics were examined by a $\chi^{2}$ test for categorical variables. An independent $t$-test was used to examine differences in continuous variables between two groups. An ROC curve was used to evaluate the diagnostic capability of how many minutes a smartphone was used before night sleep to differentiate participants from the case and control groups. The highest Youden index was chosen for the best cutoff point of smartphone usage (minutes) before night sleep. The Youden index represents a summary measurement of the
ROC curve for the accuracy of a diagnostic test. ${ }^{33}$ The AUC, sensitivity, specificity, accuracy, positive predictive value (PPV), and negative predictive value (NPV) were calculated. Otherwise, the likelihood ratios of positive ( $>$ the cutoff point of minutes of using a smartphone before night sleep; LR + ) or negative ( $\leq$ the cutoff point of minutes of using a smartphone before night sleep; LR-) were assessed. Multivariable logistic regressions were used to estimate adjusted ORs (AORs) with 95\% CIs of the association between smartphone use and breast cancer risk, after adjusting for other covariates. Candidate variables with a $p$ value of $\leq 0.10$ in the univariate analysis or had been proven as a breast cancer risk were included in the multivariable model. ${ }^{34}$ We analyzed data using SPSS vers. 18.0 (SPSS Released 2009. PASW Statistics for Windows, Chicago, IL, USA).

\section{Results}

Distributions of demographic characteristics and smartphone use between patients with breast cancer and healthy controls are shown in Table 1. There were significant differences in age, educational level, smartphone addiction, the time of using a smartphone before night sleep, placement of the smartphone when not in use, the position when using a smartphone, and sleep quality between the two groups. Compared to the controls, patients with breast cancer were significantly older, had a lower educational level, had a higher percentage addicted to smartphones, had poorer sleep quality, and were more likely to use a smartphone before night sleep as well as preferred to place their smartphone closer to their breasts. There was no significant difference in the family history of breast cancer or years having surfed the internet with a smartphone between these two groups. In addition, in the control group, there was no significant difference in distributions of demographic characteristics and smartphone use behaviors between participants recruited from the online-survey and those from the clinical outpatient department (data not shown).

Associations between smartphone use behavior and breast cancer risk are summarized in Table 2. People with smartphone addiction were more common among participants with breast cancer (61.6\%) than among healthy controls (54.4\%). After adjusting for confounding factors, participants with a smartphone addiction had a significantly increased 1.43 -fold risk (AOR $=1.43,95 \%$ $\mathrm{CI}=1.01 \sim 2.02$ ) of breast cancer compared to those without an addiction. Participants with habitual smartphone use 
Table I Distributions of Demographic Characteristics and Smartphone Use Behaviors Among Healthy Controls and Patients with Breast Cancer ( $\mathrm{N}=\mathrm{I}$ l05)

\begin{tabular}{|c|c|c|c|}
\hline Variable & $\begin{array}{l}\text { Healthy } \\
\text { Controls } \\
(\mathrm{N}=894) \\
(\%)\end{array}$ & $\begin{array}{l}\text { Patients } \\
\text { with Breast } \\
\text { Cancer } \\
(\mathrm{N}=2 \text { II) } \\
(\%)\end{array}$ & $p$ value \\
\hline $\begin{array}{l}\text { Age (years) } \\
\quad \leq 40 \\
>40\end{array}$ & $\begin{array}{l}483(54 \%) \\
4 I I(46 \%)\end{array}$ & $\begin{array}{l}38(18 \%) \\
173(82 \%)\end{array}$ & $<0.001^{a}$ \\
\hline $\begin{array}{l}\text { Educational level } \\
<\text { College } \\
\geq \text { College }\end{array}$ & $\begin{array}{l}102(11.4 \%) \\
792(88.6 \%)\end{array}$ & $\begin{array}{l}82(38.9 \%) \\
129(61.1 \%)\end{array}$ & $<0.001^{a}$ \\
\hline $\begin{array}{l}\text { Family history of breast cancer } \\
\text { Yes } \\
\text { No }\end{array}$ & $\begin{array}{l}85 \text { (9.5\%) } \\
809 \text { (90.5\%) }\end{array}$ & $\begin{array}{l}28(13.3 \%) \\
183(86.7 \%)\end{array}$ & $0.10^{\mathrm{a}}$ \\
\hline $\begin{array}{l}\text { People with smartphone addiction } \\
\text { Yes } \\
\text { No }\end{array}$ & $\begin{array}{l}486(54.4 \%) \\
408 \text { (45.6\%) }\end{array}$ & $\begin{array}{l}\text { I30 (61.6\%) } \\
81 \text { (38.4\%) }\end{array}$ & $0.04^{\mathrm{a}}$ \\
\hline $\begin{array}{l}\text { Years surfing the internet by } \\
\text { smartphone } \\
1 \sim 5 \text { years } \\
6 \sim 10 \text { years } \\
>10 \text { years }\end{array}$ & $\begin{array}{l}342(38 \%) \\
530(59 \%) \\
22(3 \%)\end{array}$ & $\begin{array}{l}89(42.2 \%) \\
114(54 \%) \\
8(3.8 \%)\end{array}$ & $0.27^{\mathrm{a}}$ \\
\hline $\begin{array}{l}\text { Posture when using a smartphone } \\
\text { (the distance between the breasts } \\
\text { and phone) } \\
\text { Placed phone on a desk } \\
(\approx 35 \mathrm{~cm}) \\
\text { Bent head down }(\approx 10 \mathrm{~cm})\end{array}$ & $\begin{array}{l}165(18.5 \%) \\
729(81.5 \%)\end{array}$ & $\begin{array}{l}30(14.2 \%) \\
181(85.8 \%)\end{array}$ & $0.03^{\mathrm{a}}$ \\
\hline $\begin{array}{l}\text { Placement of smartphone when } \\
\text { not in use } \\
\text { Below the waist (pants) } \\
\text { Waist-abdomen } \\
\text { Above the waist (chest) }\end{array}$ & $\begin{array}{l}147(16.4 \%) \\
719(80.5 \%) \\
28(3.1 \%)\end{array}$ & $\begin{array}{l}\text { II (5.2\%) } \\
192(91 \%) \\
8(3.8 \%)\end{array}$ & $<0.001^{a}$ \\
\hline $\begin{array}{l}\text { How many minutes is the } \\
\text { smartphone used before night } \\
\text { sleep } \\
\text { PSQI score }\end{array}$ & $7.57 \pm 25.00$ & $32.31 \pm 38.13$ & $0.01^{\mathrm{b}}$ \\
\hline
\end{tabular}

Notes: ${ }^{a}$ The significance of the difference was analyzed by a Chi-squared test. ${ }^{b}$ The significance of the difference was analyzed by an independent $t$-test, presented as the mean \pm standard deviation. ${ }^{~}{ }^{C}$ utoff points for age by median.

Abbreviation: PSQI, Pittsburgh Sleep Quality Index.

before night sleep also had an increased risk of having breast cancer. The Youden index showed that the best cutoff value of spending time using a smartphone before night sleep was determined to be $4.5 \mathrm{~min}$. The AUC was $81 \%(p<0.0001 ; 95 \% \mathrm{CI}=0.77 \sim 0.85)$, and the sensitivity, specificity, PPV, NPV, accuracy, and likelihood ratios of positive and negative results were $71 \%, 89 \%, 60 \%, 92 \%$,
Table 2 Adjusted Odd Ratio (AOR) and 95\% Confidence Interval $(\mathrm{Cl})$ of Smartphone Use Behaviors and Breast Cancer Risk (N=I I05)

\begin{tabular}{|c|c|c|c|}
\hline Variable & $\begin{array}{l}\text { Healthy } \\
\text { Controls } \\
(\mathrm{N}=\mathbf{8 9 4})\end{array}$ & $\begin{array}{l}\text { Patients with } \\
\text { Breast Cancer } \\
(\mathrm{N}=2 \mathrm{II})\end{array}$ & AOR $(95 \% \mathrm{Cl})$ \\
\hline \multicolumn{4}{|l|}{ Smartphone use } \\
\hline $\begin{array}{l}\text { People without } \\
\text { smartphone } \\
\text { addition } \\
\text { People with } \\
\text { smartphone } \\
\text { addition }\end{array}$ & $486(54.4 \%)$ & 81 (38.4\%) & $1.43(1.01 \sim 2.02)^{\mathrm{a}}$ \\
\hline \multicolumn{4}{|c|}{ How many minutes smartphone used before night sleep } \\
\hline $\begin{array}{l}\leq 4.5 \mathrm{~min} \\
>4.5 \mathrm{~min}\end{array}$ & $\begin{array}{l}814(91.1 \%) \\
80(8.9 \%)\end{array}$ & $\begin{array}{l}123(58.3 \%) \\
88(41.7 \%)\end{array}$ & $\begin{array}{l}1.00 \\
5.27(3.52 \sim 7.88)^{\mathrm{b}}\end{array}$ \\
\hline \multicolumn{4}{|c|}{ Posture when using smartphone (the distance between the breasts and phone) } \\
\hline $\begin{array}{l}\text { Placed phone on } \\
\text { a desk }(\approx 35 \mathrm{~cm}) \\
\text { Bent head down } \\
(\approx 10 \mathrm{~cm})\end{array}$ & $\begin{array}{l}165(18.5 \%) \\
729(81.5 \%)\end{array}$ & $\begin{array}{l}30(14.2 \%) \\
|8|(85.8 \%)\end{array}$ & $1.59(1.00 \sim 2.53)^{\mathrm{b}}$ \\
\hline \multicolumn{4}{|c|}{ Placement of smartphone when not in use } \\
\hline $\begin{array}{l}\text { Below the waist } \\
\text { (pants) }\end{array}$ & $147(16.4 \%)$ & II (5.2\%) & 1.00 \\
\hline Waist-abdomen & $719(80.5 \%)$ & $192(91 \%)$ & $4.06(2.11 \sim 7.78)^{c}$ \\
\hline $\begin{array}{l}\text { Above the waist } \\
\text { (chest) }\end{array}$ & $28(3.1 \%)$ & $8(3.8 \%)$ & $5.03(1.75 \sim 14.44)^{\mathrm{c}}$ \\
\hline
\end{tabular}

Notes: ${ }^{2}$ Adjusted for age, family history of breast cancer, educational level, quality of sleep, and placement of smartphone. ${ }^{b}$ Adjusted for age, family history of breast cancer, educational level, quality of sleep, smartphone addiction, and placement of smartphone. 'Adjusted for age, family history of breast cancer, educational level, quality of sleep, and smartphone addiction.

Abbreviations: $\mathrm{min}$, minutes; $\mathrm{cm}$, centimeter.

$85 \%, 7.1$, and 0.31 , respectively. The Youden index and optimal cutoff points are shown in Supplementary Table 1. Individuals with habitual use of a smartphone before night sleep of $>4.5 \mathrm{~min}$ had a significantly increased breast cancer risk $(\mathrm{AOR}=5.27,95 \% \mathrm{CI}=3.52 \sim 7.88)$ compared to those who used a smartphone for $\leq 4.5 \mathrm{~min}$ before night sleep after adjusting for confounders. The distance between the breasts and smartphone when in use was significantly associated with the breast cancer risk. Participants who used a phone while bending the head down (holding the smartphone in the hand, such that the distance between the smartphone and breasts was around $10 \mathrm{~cm}$ ) had a significantly increased 1.59-fold risk $(\mathrm{AOR}=1.59,95 \% \mathrm{CI}=1.00 \sim 2.53)$ of breast cancer compared to those put the phone on a desk (with the distance 
between the smartphone and the breasts of around $35 \mathrm{~cm}$ ) when using the smartphone. The major region where the smartphone was placed when not in use was also significantly related to the risk of breast cancer. Individuals who placed the smartphone in the chest area (such as keeping it in a bra or hanging it around the neck near the breasts) or in the waist-abdominal area had significantly increased 5.03-fold risk $(\mathrm{AOR}=5.03,95 \% \mathrm{CI}=1.75 \sim 14.44)$ and 4.06fold risk $(\mathrm{AOR}=4.06,95 \% \mathrm{CI}=2.11 \sim 7.78)$, respectively, of breast cancer compared to those who carried their smartphone in the area below the waist.

The synergistic effect between smartphone addiction and time spent on the smartphone before night sleep on the breast cancer risk is shown in Table 3. A synergistic effect between smartphone addiction and smartphone use before night sleep was found. Participants with smartphone addiction and habitual use of a smartphone before night sleep of $>4.5$ min or non-addicts but with habitual use of a smartphone before night sleep of $>4.5 \mathrm{~min}$ had significantly increased 6.88-fold risk $(\mathrm{AOR}=6.88,95 \%$ $\mathrm{CI}=4.07 \sim 11.61)$ and 3.24-fold risk $(\mathrm{AOR}=3.24,95 \%$ $\mathrm{CI}=1.62 \sim 6.44)$, respectively, of breast cancer compared to those who had neither smartphone addiction nor smartphone use of $>4.5 \mathrm{~min}$ before night sleep.

Table 3 Adjusted Odd Ratio (AOR) and 95\% Confidence Interval $(\mathrm{Cl})$ of the Synergistic Effect Between People with Smartphone Addiction and the Time Spent on Smartphone Use Before Night Sleep on the Breast Cancer Risk ( $\mathrm{N}=$ I I05)

\begin{tabular}{|c|c|c|c|}
\hline Variable & $\begin{array}{l}\text { Healthy } \\
\text { Controls } \\
(\mathrm{N}=894)\end{array}$ & $\begin{array}{l}\text { Patients with } \\
\text { Breast } \\
\text { Cancer } \\
(\mathrm{N}=21 \mathrm{I})\end{array}$ & $\begin{array}{l}\text { AOR }(95 \% \\
\mathrm{Cl})\end{array}$ \\
\hline $\begin{array}{l}\text { People without smartphone } \\
\text { addiction and } \\
\text { smartphone use of } \leq 4.5 \mathrm{~min} \\
\text { before night sleep }\end{array}$ & $\begin{array}{l}377 \\
(42.2 \%)\end{array}$ & 56 (26.5\%) & 1.00 \\
\hline $\begin{array}{l}\text { People with smartphone } \\
\text { addiction and smartphone use } \\
\text { of } \leq 4.5 \mathrm{~min} \text { before night sleep }\end{array}$ & $\begin{array}{l}437 \\
(48.8 \%)\end{array}$ & 67 (31.8\%) & $\begin{array}{l}1.04 \\
(0.69 \sim 1.58)\end{array}$ \\
\hline $\begin{array}{l}\text { People without smartphone } \\
\text { addiction and smartphone use } \\
\text { of }>4.5 \text { min before night sleep }\end{array}$ & 31 (3.5\%) & 22 (10.4\%) & $\begin{array}{l}3.24 \\
(1.62 \sim 6.44)\end{array}$ \\
\hline $\begin{array}{l}\text { People with smartphone } \\
\text { addiction and smartphone use } \\
\text { of }>4.5 \text { min before night sleep }\end{array}$ & 49 (5.5\%) & 66 (31.3\%) & $\begin{array}{l}6.88 \\
(4.07 \sim 11.61)\end{array}$ \\
\hline
\end{tabular}

Note: The AOR was adjusted for age, family history of breast cancer, educational level, placement of smartphone, and quality of sleep.

Abbreviation: min, minutes.

\section{Discussion}

To the best of our knowledge, we are the first to find that excessive smartphone use significantly increased the risk of breast cancer, particular for participants with a smartphone addiction, who maintained a close distance between the breasts and smartphone, and who had the habit of smartphone use before bedtime. Moreover, there was a synergistic effect between smartphone addiction and habitual smartphone use of $>4.5 \mathrm{~min}$ before night sleep of increasing the breast cancer risk.

White et $\mathrm{al}^{35}$ conducted a prospective cohort study to investigate the relationship between the quality of sleep and breast cancer. They identified 41,474 participants who were breast cancer-free at the baseline and completed baseline questionnaires on sleep characteristics. After 7 years of follow-up, 2736 new breast cancer cases (invasive and ductal carcinoma in situ) had been diagnosed. They found that participants who suffered from difficulty sleeping $\geq 4$ nights per week were at an overall increased risk of breast cancer (hazard ratio $(\mathrm{HR})=1.32, \quad 95 \%$ $\mathrm{CI}=1.09 \sim 1.61)$ compared to those with difficulty sleeping $<1$ night per week. ${ }^{35}$ Our investigation results were consistent with those of White et al, as we found that the quality of sleep among patients with breast cancer was significantly worse $(p=0.01)$ than that of healthy controls.

Smartphone addiction was reported to have negative impacts on health because of making changes in a person's lifestyle, including a general decrease in physical activity, neglecting one's health status, and avoiding outside activities, in order to spend more time on the internet. ${ }^{2}$ Additionally, some laboratory studies also demonstrated that radiofrequency fields accelerate the development of sarcoma colonies in the lungs, mammary tumors, skin tumors, hepatomas, sarcomas, and brain tumors. ${ }^{7-11}$ In our study, we found that participants with a smartphone addiction had a significantly increased 1.43-fold risk of breast cancer compared to those without addiction. Our results suggest that people with smartphone addiction could have massive radiofrequency exposure compared to people without smartphone addiction, ${ }^{36,37}$ therefore increasing their risk of developing breast cancer.

Individuals with habitual use of a smartphone of $>4.5 \mathrm{~min}$ before night sleep had a significantly increased breast cancer risk $(\mathrm{AOR}=5.27,95 \% \mathrm{CI}=3.52 \sim 7.88)$ compared to those who used a smartphone for $\leq 4.5 \mathrm{~min}$ before night sleep after adjusting for confounding factors. This result was also supported by Chang et al, ${ }^{16}$ who conducted a randomized 
controlled trial to estimate the effect of an electro-device book on melatonin expression. They randomized their participants into two conditions: (i) reading an electro-device book, such as an iPad notebook or Kindle for $4 \mathrm{~h}$ before bedtime for five consecutive evenings, and (ii) reading a printed book for the same duration. Their results showed that the electro-device condition suppressed evening levels of melatonin by $55.12 \% \pm 20.12 \%$, whereas the printed-book condition showed no suppression as measured on the fifth night $(p<0.001)$. Also, the electro-device condition delayed the onset of melatonin release. The onset of melatonin release was significantly deferred $(p<0.001)$ among participants in the electro-device condition $(22: 31 \pm 00: 42)$ compared to those in the printed-book condition $(21: 01 \pm 00: 49) .{ }^{16}$ They highlighted that use of electro-devices before bedtime prolonged the time of falling asleep, delayed the circadian clock, suppressed levels of the sleep-promoting hormone melatonin, and reduced the amount of and delayed the timing of rapid eye movement (REM) sleep. ${ }^{16,18}$ Some studies also reported that circadian disruption favors the induction and/ or promotion of malignant breast tumor development. ${ }^{35,38-40}$ A similar result was found by White et $\mathrm{al}^{35}$ that the risk of breast cancer was significantly elevated in women who reported having a light or television on in the room while sleeping. We suggest that using a smartphone before bedtime causes participants to be exposed to short-wavelengthenriched light emitted by these electronic devices, which contributes to suppression of melatonin expression at night and a phase-shift in the biological clock. ${ }^{18}$ Because melatonin plays an important role in inhibiting the release of estrogen, a risk factor for breast cancer, and also for suppressing the development of breast cancer, ${ }^{38-41}$ we considered that inhibiting melatonin expression and inducing circadian disruption due to smartphone use before bedtime can result in a propensity for breast cancer development.

Participants who were used to bending their head down (holding the smartphone in the hand; with a distance between the smartphone and breasts of around $10 \mathrm{~cm}$ ) when using a smartphone had an increased 1.59fold risk of having breast cancer compared to those who put the phone on a desk (with the distance between the smartphone and breasts of around $35 \mathrm{~cm}$ ). An experimental study demonstrated that using smartphones and Wi-Fi radiation sources which were at least $10 \mathrm{~cm}$ away may provide useful distance against oxidative stress, apoptosis, and overload $\mathrm{Ca}^{+}$entry in cancer. Radiofrequency radiation exposure is significantly associated with intracellular ROS production when smartphones or WiFi sources are placed within $10 \mathrm{~cm}$ of cells, which induced excessive oxidative responses and apoptosis via transient receptor potential vanilloid 1 (TRPV1)-induced cytosolic $\mathrm{Ca}^{2+}$ accumulation in breast cancer cells. ${ }^{42}$ This result is consistent with our study, of a shorter distance between the breasts and smartphone increasing the risk of breast cancer. Therefore, we suggest that a closer distance between the smartphone and breast benefits exposure and transmission of radiofrequencies emitted from the smartphone to the breasts, and contributes to ROS production, thereby promoting the development of breast cancer, ${ }^{43}$ and thus maintaining a sufficient distance between the smartphone and breasts of at least $35 \mathrm{~cm}$ in all situations are strongly recommended.

Individuals who were used to placing the smartphone on the region near the chest area or waist-abdomen area when it was not in use had a significantly increased 5.03fold risk and 4.06-fold risk, respectively, of having breast cancer compared to those who carried the smartphone in the area below the waist. Regarding the shorter distance between the breast and smartphone placement, that could increase the risk of breast cancer, an interesting case report consisted of four young women aged 21 39 years, who exhibited no family history of breast cancer and tested negative for BRCA1 and BRCA2. Their breast imaging was reviewed and demonstrated clusters of multiple tumor foci in the breast directly under the area of phone contact, and further, participants who regularly carried their mobile phones close to their breast area for a period of up to 10 $\mathrm{h}$ a day were found to be at higher susceptibility of developing tumors in their breasts. ${ }^{44}$

It is noteworthy that we found a synergistic effect between smartphone addiction and smartphone use of $>4.5 \mathrm{~min}$ before night sleep increasing the breast cancer risk. Participants who were both addicted to their smartphone and used their smartphone for $>4.5 \mathrm{~min}$ before night sleep and participants who were not addicted to their smartphones but used the smartphone for $>4.5$ min before night sleep, respectively, had increased risks of breast cancer of 6.88-fold and 3.24-fold compared to those who were neither addicted to their smartphone nor used their smartphone for $>4.5 \mathrm{~min}$ before night sleep. We suggest that the potential mechanism relating to the synergistic effect of smartphone addiction and using a smartphone for $>4.5 \mathrm{~min}$ before night sleep on the risk of breast cancer could be due to these two risk factors being prone to expose participants to radiofrequencies and circadian 
disruption. Smartphone-emitted radiofrequency radiation induces the creation of ROS, which contribute to DNA mutations and carcinogenesis. $^{13}$ Circadian disruption results in the inhibition and delay of melatonin expression, ${ }^{17}$ consequently decreasing the quality of sleep and benefiting the release of estrogen, which promotes the development of breast cancer. ${ }^{45-47}$

\section{Limitations}

This study provides important findings that incorrect smartphone use habits can be potential risk factors for breast cancer. However, there were some limitations to our study. First, all patients with breast cancer were recruited from a hospital, while the control group was recruited from both the hospital and an online survey. Among the control group, the inclusion criteria for controls were identical, and there were no significant differences in the distributions of demographic characteristics or smartphone use behaviors between the healthy controls recruited from the hospital and those from the online survey. Despite this, we noted that demographics differed between the case and control groups; therefore, we used a univariate analysis to adjust all covariates in the multivariable model. We consider that this limitation should not have induced non-comparability between the case and control groups or any overestimation of our results. Second, placement of the smartphone and posture when using a smartphone may vary in a day. Exposure to radiation depends on the length of time and frequency of use, which vary from individual to individual, and these variables might not be accurately assessed by a questionnaire. Third, all of the instruments were assessed using selfreporting, and the major problem with self-reporting is recall bias. Finally, some variables of the self-constructed questionnaire for demographic data collected, such as the use of smartphones before night sleep, posture when using a smartphone, and placement of the smartphone, might not have provided precise answers. Consequently, future studies might consider using objective measuring instruments (a tracking app to assess time spent on surfing the smartphone each day and a tracking app of distance/placement when using the smartphone) could more precisely and objectively measure the variables examined.

\section{Conclusions}

Smartphone addiction, smartphone use of $>4.5 \mathrm{~min}$ before bedtime, and a close distance between the smartphone and the bosom significantly increased the breast cancer risk.
Moreover, the combination of smartphone addiction and smartphone use of $>4.5 \mathrm{~min}$ before bedtime synergistically increased the breast cancer risk.

\section{Ethics Approval and Consent to Participate}

This study was approved by the Ethics Committee of the Taipei Medical University Hospital Institutional Review Board (no. N201709040) (source deleted for blinded review) and conformed to the Declaration of Helsinki. All participants provided written informed consent before study enrollment. None of the patients who provided consent was eliminated from the study. All methods were performed in accordance with relevant guidelines and regulations.

\section{Acknowledgments}

Our appreciation is extended to every researcher and participant who contributed to this study. This study was supported by grant nos. MOST 106-2314-B-038-013MY3 and MOST 109-2314-B-038-110- from the Ministry of Science and Technology, Taiwan. The funders had no role in the study design, data collection and analysis, decision to publish, or preparation of the manuscript.

\section{Author Contributions}

All authors made a significant contribution to the work reported, whether in the conception, study design, execution, acquisition of data, analysis and interpretation, or in all these areas; took part in drafting, revising, or critically reviewing the article; gave final approval of the version to be published; have agreed on the journal to which the article has been submitted; and agree to be accountable for all aspects of the work.

\section{Disclosure}

The authors report no conflicts of interest with regard to this work.

\section{References}

1. Union IT. ICT Facts and Figures. 2014.

2. Bidi F, Namdari-Pejman M, Kareshki H, Ahmadnia H. The mediating role of metacognition in the relationship between internet addiction and general health. Addict Health. 2012;4(1-2):49-56.

3. Davey S, Davey A, Raghav SK, et al. Predictors and consequences of "phubbing" among adolescents and youth in India: an impact evaluation study. J Family Community Med. 2018;25(1):35-42.

4. Hales AH, Dvir M, Wesselmann ED, Kruger DJ, Finkenauer C. Cell phone-induced ostracism threatens fundamental needs. J Soc Psychol. 2018;1-14. 
5. Lodi M, Scheer L, Reix N, et al. Breast cancer in elderly women and altered clinico-pathological characteristics: a systematic review. Breast Cancer Res Treat. 2017;166(3):657-668. doi:10.1007/s10549-017-4448-5

6. Health Promotion Administration MoHaW. Health Promotion Administration Annual Report. 2017.

7. Grell K, Frederiksen K, Schuz J, et al. The Intracranial distribution of gliomas in relation to exposure from mobile phones: analyses from the INTERPHONE study. Am J Epidemiol. 2016;184(11):818-828. doi:10.1093/aje/kww082

8. Belyaev I, Dean A, Eger H, et al. EUROPAEM EMF guideline 2016 for the prevention, diagnosis and treatment of EMF-related health problems and illnesses. Rev Environ Health. 2016;31(3):363-397.

9. Alkan A, Kutuk T, Karci E, Yasar A, Hicsonmez A, Utkan G. Radiationinduced tumor lysis syndrome in chronic lymphocytic leukemia. Turk J Haematol. 2016;33(3):248-250. doi:10.4274/tjh.2015.0259

10. Morgan LL, Miller AB, Sasco A, Davis DL. Mobile phone radiation causes brain tumors and should be classified as a probable human carcinogen (2A) (review). Int $J$ Oncol. 2015;46(5):1865-1871. doi:10.3892/ijo.2015.2908

11. Wiedemann PM, Boerner FU, Repacholi MH. Do people understand IARC's 2B categorization of RF fields from cell phones? Bioelectromagnetics. 2014;35(5):373-378. doi:10.1002/bem.21851

12. Haus EL, Smolensky MH. Shift work and cancer risk: potential mechanistic roles of circadian disruption, light at night, and sleep deprivation. Sleep Med Rev. 2013;17(4):273-284. doi:10.1016/j.smrv.2012.08.003

13. Esmekaya MA, Canseven AG, Kayhan H, Tuysuz MZ, Sirav B, Seyhan N. Mitochondrial hyperpolarization and cytochrome-c release in microwave-exposed MCF-7 cells. Gen Physiol Biophys. 2017;36 (2):211-218. doi:10.4149/gpb_2016021

14. Hardell L. World Health Organization, radiofrequency radiation and health - a hard nut to crack (Review). Int J Oncol. 2017;51 (2):405-413. doi:10.3892/ijo.2017.4046

15. Chen Q, Lang $\mathrm{L}, \mathrm{Wu} \mathrm{W}$, et al. A meta-analysis on the relationship between exposure to ELF-EMFs and the risk of female breast cancer. PLoS One. 2013;8(7):e69272. doi:10.1371/journal.pone.0069272

16. Chang AM, Aeschbach D, Duffy JF, Czeisler CA. Evening use of light-emitting eReaders negatively affects sleep, circadian timing, and next-morning alertness. Proc Natl Acad Sci U S A. 2015;112 (4):1232-1237. doi:10.1073/pnas.1418490112

17. Wong HY, Mo HY, Potenza MN, et al. Relationships between severity of internet gaming disorder, severity of problematic social media use, sleep quality and psychological distress. Int J Environ Res Public Health. 2020;17(6). doi:10.3390/ijerph17061879.

18. Lin CY, Imani V, Griffiths MD, et al. Temporal associations between morningness/eveningness, problematic social media use, psychological distress and daytime sleepiness: mediated roles of sleep quality and insomnia among young adults. J Sleep Res. 2020;e13076.

19. Alimoradi Z, Lin CY, Broström A, et al. Internet addiction and sleep problems: a systematic review and meta-analysis. Sleep Med Rev. 2019;47:51-61. doi:10.1016/j.smrv.2019.06.004

20. Coureau G, Bouvier G, Lebailly P, et al. Mobile phone use and brain tumours in the CERENAT case-control study. Occup Environ Med. 2014;71(7):514-522. doi:10.1136/oemed-2013-101754

21. Kesari KK, Siddiqui MH, Meena R, Verma HN, Kumar S. Cell phone radiation exposure on brain and associated biological systems. Indian J Exp Biol. 2013;51(3):187-200.

22. Hardell L, Carlberg M, Soderqvist F, Mild KH. Case-control study of the association between malignant brain tumours diagnosed between 2007 and 2009 and mobile and cordless phone use. Int J Oncol. 2013;43(6):1833-1845. doi:10.3892/ijo.2013.2111

23. Momoli F, Siemiatycki J, McBride ML, et al. Probabilistic multiple-bias modeling applied to the Canadian data from the interphone study of mobile phone use and risk of glioma, meningioma, acoustic neuroma, and parotid gland tumors. Am J Epidemiol. 2017;186(7):885-893. doi:10.1093/aje/kwx157
24. Brignardello-Petersen R. Cell phone use may increase the risk of developing parotid gland tumors. J Am Dent Assoc. 2017;148(5):e61.

25. Sato Y, Akiba S, Kubo O, Yamaguchi N. A case-case study of mobile phone use and acoustic neuroma risk in Japan. Bioelectromagnetics. 2011;32(2):85-93. doi:10.1002/bem.20616

26. Hardell L, Eriksson M, Carlberg M, Sundstrom C, Mild KH. Use of cellular or cordless telephones and the risk for non-Hodgkin's lymphoma. Int Arch Occup Environ Health. 2005;78(8):625-632. doi:10.1007/s00420-005-0003-5

27. Hardell L, Carlberg M, Ohlson CG, Westberg H, Eriksson M, Hansson Mild K. Use of cellular and cordless telephones and risk of testicular cancer. Int J Androl. 2007;30(2):115-122. doi:10.1111/ j.1365-2605.2006.00721.x

28. Szmigielski S. Cancer risks related to low-level RF/MW exposures, including cell phones. Electromagn Biol Med. 2013;32(3):273-280. doi:10.3109/15368378.2012.701192

29. Hardell L, Carlberg M. Comments on the US national toxicology program technical reports on toxicology and carcinogenesis study in rats exposed to whole-body radiofrequency radiation at $900 \mathrm{MHz}$ and in mice exposed to whole-body radiofrequency radiation at 1900 MHz. Int J Oncol. 2019;54(1):111-127.

30. Buysse DJ, Reynolds CF 3rd, Monk TH, Berman SR, Kupfer DJ. The Pittsburgh sleep quality index: a new instrument for psychiatric practice and research. Psychiatry Res. 1989;28(2):193-213. doi:10.1016/0165-1781(89)90047-4

31. Tsai PS, Wang SY, Wang MY, et al. Psychometric evaluation of the Chinese version of the Pittsburgh sleep quality index (CPSQI) in primary insomnia and control subjects. Qual Life Res. 2005;14 (8):1943-1952. doi:10.1007/s11136-005-4346-X

32. Lin YH, Pan YC, Lin SH, Chen SH. Development of short-form and screening cutoff point of the smartphone addiction inventory (SPAI-SF). Int J Methods Psychiatr Res. 2017;26(2).

33. Fluss R, Faraggi D, Reiser B. Estimation of the youden index and its associated cutoff point. Biom J. 2005;47(4):458-472. doi:10.1002/ bimj.200410135

34. Bursac Z, Gauss CH, Williams DK, Hosmer DW. Purposeful selection of variables in logistic regression. Source Code Biol Med. 2008;3 (1):17. doi:10.1186/1751-0473-3-17

35. White AJ, Weinberg CR, Park YM, et al. Sleep characteristics, light at night and breast cancer risk in a prospective cohort. Int $J$ Cancer. 2017;141(11):2204-2214.

36. Miah T, Kamat D. Current understanding of the health effects of electromagnetic fields. Pediatr Ann. 2017;46(4):e172-e174. doi:10.3928/19382359-20170316-01

37. Mortazavi SMJ, Mortazavi SAR, Paknahad M. Evaluation of the potential of mobile phone specific electromagnetic fields (UMTS) to produce micronuclei in human glioblastoma cell lines. Toxicol in Vitro. 2017;44:414-415. doi:10.1016/j.tiv.2017.07.029

38. Liu L, Ancoli-Israel S. Sleep disturbances in cancer. Psychiatr Ann. 2008;38(9):627-634. doi:10.3928/00485713-20080901-01

39. Soucise A, Vaughn C, Thompson CL, et al. Sleep quality, duration, and breast cancer aggressiveness. Breast Cancer Res Treat. 2017;164 (1):169-178. doi:10.1007/s10549-017-4245-1

40. Kakizaki M, Kuriyama S, Sone T, et al. Sleep duration and the risk of breast cancer: the ohsaki cohort study. Br J Cancer. 2008;99 (9):1502-1505. doi:10.1038/sj.bjc.6604684

41. Stothard ER, McHill AW, Depner CM, et al. Circadian entrainment to the natural light-dark cycle across seasons and the weekend. Curr Biol. 2017;27(4):508-513. doi:10.1016/j.cub.2016.12.041

42. Çiğ B, Nazıroğlu M. Investigation of the effects of distance from sources on apoptosis, oxidative stress and cytosolic calcium accumulation via TRPV1 channels induced by mobile phones and Wi-Fi in breast cancer cells. Biochim Biophys Acta. 2015;1848(10 Pt B):2756-2765. doi:10.1016/j.bbamem.2015.02.013 
43. Feychting M, Ahlbom A, Kheifets L. EMF and health. Annu Rev Public Health. 2005;26(1):165-189. doi:10.1146/annurev. publhealth.26.021304.144445

44. West JG, Kapoor NS, Liao SY, Chen JW, Bailey L, Nagourney RA. Multifocal breast cancer in young women with prolonged contact between their breasts and their cellular phones. Case Rep Med. 2013;2013:354682. doi:10.1155/2013/354682

45. Pekovic-Vaughan V, Gibbs J, Yoshitane H, et al. The circadian clock regulates rhythmic activation of the NRF2/glutathione-mediated antioxidant defense pathway to modulate pulmonary fibrosis. Genes Dev. 2014;28(6):548-560. doi:10.1101/gad.237081.113
46. Hakim F, Wang Y, Zhang SX, et al. Fragmented sleep accelerates tumor growth and progression through recruitment of tumor-associated macrophages and TLR4 signaling. Cancer Res. 2014;74(5):1329-1337. doi:10.1158/0008-5472.CAN-13-3014

47. Gozal D, Almendros I, Hakim F. Sleep apnea awakens cancer: a unifying immunological hypothesis. Oncoimmunology. 2014;3(4): e28326. doi:10.4161/onci.28326

\section{Publish your work in this journal}

Cancer Management and Research is an international, peer-reviewed open access journal focusing on cancer research and the optimal use of preventative and integrated treatment interventions to achieve improved outcomes, enhanced survival and quality of life for the cancer patient.
The manuscript management system is completely online and includes a very quick and fair peer-review system, which is all easy to use. Visit http://www.dovepress.com/testimonials.php to read real quotes from published authors. 